\title{
Probiotic drink from the fermentation of banana flower (Ontong) with addition of kluthuk banana leaves (Musa balbisiana)
}

\author{
R. Rompies ${ }^{1}$, F. Nurkolis ${ }^{2}$, H. Natanael ${ }^{1}$, J. I. Ch. Manoppo ${ }^{1}$, N. Mayulu ${ }^{3}$, S. Kawengian ${ }^{3}$ and \\ Y. A. Assa ${ }^{3}$ \\ ${ }^{1}$ Department of Pediatrics, Sam Ratulangi University/Prof.dr.R.D.Kandou Hospital Manado, Raya Tanawangko 56 \\ street, Manado, Indonesia, \\ ${ }^{2}$ Department of Biological Sciences, Faculty of Sciences and Technology, State Islamic University of Sunan Kalijaga, \\ Yogyakarta 55281, Indonesia and \\ ${ }^{3}$ Food and Nutrition Department of Sam Ratulangi University, Kampus Unsrat Bahu Street, Indonesia
}

There is a lot of agricultural waste that still needs to be used for efficient products, such as banana flower or Ontong and banana leaves. Based on the studies, banana flowers and banana leaves (Musa balbisiana), especially the type of kluthuk, contain high nutrients, such as fibre and starch and other bioactives ${ }^{(1)}$. However, its use for health products is still lacking. This study aims to process or formulate and utilize banana flowers and banana leaves of the kluthuk type to become a functional food product in the form of fermented drinks. In addition, it is also to determine the levels of antioxidants (especially vitamin C) in fermented products in vitro.

There are 3 variations of the formulation, Banana Flower: Banana Leaf: CO2 free water. Sample 1 (1: 0.5: 0.5), sample 2 (2: 1: 1) and sample 3 (3: 2: 2). Then, all product samples were inoculated with Lactobacillus paracasei for 14 days under anaerobic conditions. Sample variation was carried out to determine the significance of the average antioxidant content in it. The next step was to test the analysis of vitamin C from 3 samples of cookies using the Iodometric Titration Method, to determine the amount of Vitamin C (mg/ $100 \mathrm{~g}$ ) and the antioxidant activity with 2.2-diphenyl-1-picrylhydrazyl (DPPH) with triple repeat per sample.

The amount of vitamin C obtained at S1 was $60.40 \pm 1.00 \mathrm{mg} / 100 \mathrm{~g}$ with $15.55 \pm 0.05 \%$ antioxidant activity, S2 was $55.95 \pm 0.05 \mathrm{mg} /$ $100 \mathrm{~g}$ with $10.60 \pm 0.30 \%$ antioxidant activity and $\mathrm{S} 3$ was $77.92 \pm 0.02 \mathrm{mg} / 100 \mathrm{~g}$ with $22.10 \pm 0.10 \%$ antioxidant activity. The fermented drink sample formulation containing the highest vitamin $\mathrm{C}$ was $\mathrm{S} 3$. There was a significant difference $(\mathrm{P}<0.05)$ which determined the vitamin $\mathrm{C}$ levels between the sample formulations. The average ash content of the three samples was $2.40 \pm 0.40 \%$ and the moisture content was $35.60 \pm 5.00 \%$. The average vitamin C level in the three fermented drink samples was $64.75 \pm 11.61 \mathrm{mg} / 100 \mathrm{~g}$. S3 showed the best activity, namely antioxidant activity against 2.2-diphenyl-1-picrylhydrazyl (DPPH) of $22.10 \pm 0.10 \%$.

The combination of kluthuk banana flowers and leaves has a great potential to be developed into health functional food. By looking at the content of vitamin $\mathrm{C}$ and antioxidants in the fermented products, it can be an effort to diversify local food and also become a good drink during the pandemic, because antioxidants have the ability to increase immunity and anti-inflammation ${ }^{(2)}$. This product also contains prebiotics and probiotics which are good for the gut microbiome which play a good role in the immune system. Therefore, these product can be a potential Anti SARS-CoV-2, which SARS-Cov-2 itself attacks immunity and causes inflammation in the body3. Animal studies are needed to find out the interactions between substances before they are tested in humans.

\section{Acknowledgements}

We thank to all of contributors for their outstanding help in formatting the abstract, especially Fahrul Nurkolis who has fully assisted in laboratory tests. The authors' responsibilities were as follows - all authors: contributed to the writing and revisions contained in the abstract; and all authors have read and approved the final abstract.

\section{References}

1. Hapsari L, \& Lestari DA (2016) AGRIVITA, J Agric Sci 38(3), 303-311.

2. Biesalski HK, Grune T, Tinz J, et al. (2010) Nutrients 2(9), 929-949.

3. Shinde T, Hansbro PM, Sohal, SS, et al. (2020) Microorganisms, 8(6), 921. 